\title{
O ESTADO FEDERADO BRASILEIRO, AS RELAÇÕES ENTRE OS PODERES, O DIREITO DE PARTICIPAÇÃO POPULAR E AS REGIÕES METROPOLITANAS
}

\author{
Eunice Aparecida de Jesus Prudente* \\ Assistente do Departamento de Direito do Estado da Faculdade de Direito da USP \\ Paulo José Villela Lomar ${ }^{* *}$ \\ Mestrando da Faculdade de Direito da Pontifícia Universidade Católica
}

Resumo:

Análise da organização metropolitana na Constituição Federal Brasileira de 1988 e na Constituição Estadual de São Paulo de 1989. Estudo Comparativo das Leis Complementares instituidoras das regiões metropolitanas nos Estados do Rio de Janeiro, Minas Gerais, Pernambuco e São Paulo. Comentários à Lei Complementar n. 760, de $1^{\circ}$ de agosto de 1994.

\begin{abstract}
:
Analysis metropolitan areas organization in the 1988 Brazilian Federal Constitution and the 1989 São Paulo Constitution. Comparative study of the Lawwhich stabilished metropolitan areas in the following states: Rio de Janeiro, Minas Gerais, Pernambuco and São Paulo. Coments about the São Paulo State Law n. 760, dated August 1st., 1994.
\end{abstract}

Unitermos: Constituição Federal de 1988; Constituição Estadual de São Paulo de 1989.

* Advogada da Empresa Metropolitana de Planejamento da Grande São Paulo S.A. - Emplasa.

** Chefe da Assessoria Jurídica para Assuntos Institucionais da Empresa Metropolitana de Planejamento da Grande São Paulo S.A. - Emplasa. 


\section{I - A Gestão Metropolitana Compartilhada}

\section{Fundamentos Constitucionais Nacionais}

A nova ordem constitucional vigente foi, pela primeira vez na história constitucional brasileira, precedida por significativo movimento constituinte.

Manifestação do poder constituinte originário prevê entre os objetivos fundamentais da República Federativa do Brasil: ...erradicar a pobreza $e$ a marginalização e reduzir as desigualdades sociais e regionais" (art. $3^{\circ}$ ) com vistas a constituir-se em Estado Democrático de Direito, tendo como fundamentos, a soberania, a cidadania; a dignidade da pessoa humana; os valores sociais do trabalho e da livre iniciativa e o pluralismo político (art. $1^{\circ}$ ).

Saliente-se que o Estado Democrático de Direito, assim preconizado na Constituição Federal, revela um tipo de Welfare State quando acolhe uma ordem social asseguradora dos direitos relativos à saúde, à previdência social, à assistência social, responsabilizando-se pela educação e cultura, como direito fundamental a todos os cidadãos. Fundamenta a ordem econômica e financeira na valorização do trabalho humano e na livre iniciativa, a fim de "assegurar a todos existência digna, conforme os ditames da justiça social" observados os princípios: soberania nacional, propriedade privada, função social da propriedade, livre concorrência, defesa do consumidor, defesa do meio ambiente, redução das desigualdades regionais e sociais, busca do pleno emprego e o tratamento favorecido para as empresas brasileiras de capital nacional de pequeno porte (arts. 170, 193 e ss.).

Tais disposições ensejaram concomitante alteração na forma de Estado, ou seja, o Brasil tem hoje um federalismo cooperativo, no qual os entes federados possuem competências comuns e concorrentes (arts. 23 e 24). União, Estados e Municípios preservam o meio ambiente, promovendo o município o ordenamento territorial, mediante planejamento e controle do uso, do parcelamento e da ocupação do solo urbano (art. 30, VIII); aos Estados e estabelecimento de áreas de proteção ambiental e fiscalização de seu uso (art. 24, I) a partir de normas gerais criadas pela União. 
2. Organização Regional: Rio de Janeiro, Minas Gerais, Pernambuco e São Paulo

A Constituição Federal de 1988 transferiu da União para o Estado Federado o poder discricionário de criar as regiões metropolitanas como unidades territoriais, abrangendo um conjunto de Municípios agrupados com base nos efeitos de polarização consubstanciada no fluxo de pessoas, mercadorias e outros aspectos de natureza geográfica, urbanística, econômica e ambiental.

O legislador constituinte atribuiu, portanto, ao Estado Federado a responsabilidade pela solução dos problemas metropolitanos, no âmbito de sua competência residual, mediante a integração do planejamento, da organização e da execução de funções públicas de interesse comum ao Estado Federado e aos Municípios agrupados nesta unidade territorial. Embora a responsabilidade seja estadual, a Constituição Federal estabeleceu, implicitamente, que o seu exercício deveria ser compartilhado com os Municípios da região metropolitana. De fato, a criação de unidades territoriais, como as regiões metropolitanas poderia ser efetuada pelo Estado Federado como instrumento de descentralização coordenada de suas ações independentemente da autorização constitucional expressa no $\S 3^{\circ}$ do art. 25. Esta explicitação, para consubstanciar um significado jurídico distinto daquele que resultaria da omissão desta autorização no texto constitucional, conota exatamente o exercício dessa responsabilidade de modo compartilhado com os Municípios da região metropolitana, porque somente assim será possível integrar o planejamento, a organização e a execução de funções públicas de interesse comum.

A partir da aprovação de suas Constituições Estaduais, em 1989, alguns Estados Federados puseram-se a atualizar os antigos modelos de gestão até então vigentes nas regiões metropolitanas.

Dentre estes Estados, o do Rio de Janeiro foi o primeiro a fazê-lo mediante a Lei Complementar Estadual n. 64, de 21 de setembro de 1990. Por força deste diploma legal, a Região Metropolitana do Rio de Janeiro passou a ser gerida por órgão do Poder Executivo, incumbido da elaboração e supervisão da execução dos planos, programas e projetos relacionados às funções públicas e serviços de interesse comum, consubstanciadas no Plano Diretor Metropolitano e de outros encargos que the forem atribuídos pelo Conselho Deliberativo da Região Metropolitana do Rio de Janeiro (vide inciso I do art. $5^{\circ}$ da referida Lei Complementar n. 64/90). 
Este Conselho Deliberativo, nos termos do art. $4^{\circ}$ da Lei Complementar n. 64/90, recebeu, dentre outras, as atribuições de:

- submeter à Assembléia Legislativa o Plano Diretor Metropolitano;

- exercer o poder normativo referente à integração do planejamento, da organização e da execução de funções públicas de interesse comum; e

- definir os parâmetros de compensação financeira aos Municípios.

A composição do mesmo Conselho, conforme o art. $3^{\circ}$ da Lei Complementar n. 64/90, abrange como seus membros:

- os prefeitos dos Municípios da Região Metropolitana do Rio de Janeiro;

- um vereador indicado por cada uma das Câmaras Municipais da Região Metropolitana;

- cinco representantes da Assembléia Legislativa, por ela indicados;

- cinco representantes do Poder Executivo, indicados pelo Governador do Estado, escolhidos entre Secretários de Estado que dirijam órgãos relacionados com as funções públicas comuns;

um representante de entidades comunitárias, indicado pelo

Governador;

um representante da sociedade civil, indicado pelo Governador.

A Presidência do Conselho será exercida pelo Governador do Estado, substituído, em seus impedimentos, pelo Secretário de Estado incumbido dos assuntos metropolitanos.

$\mathrm{O}$ art. $2^{\circ}$ da Lei Complementar n. 64/90 considera de interesse comum as funções públicas e serviços que atendam a mais de um município, assim como os que, restritos ao território de um deles, sejam de algum modo dependentes, concorrentes ou confluentes de funções públicas e serviços supramunicipais, notadamente: planejamento integrado, saneamento básico e ambiental, transportes coletivos de âmbito metropolitano, a programação de rede viária, do tráfego e dos terminais de passageiros e carga, habitação, cartografia e informações básicas para o planejamento metropolitano.

Finalmente, entre outras disposições legais, o art. 10 ratificou o fundo metropolitano, dando-lhe nova denominação: Fundo de Desenvolvimento Metropolitano, constituído de recursos de natureza orçamentária e extraorçamentária, produto de operações de crédito internas e externas. 
Em 14 de janeiro de 1993, entrou em vigor a Lei Complementar n. 26, do Estado de Minas Gerais, que estabelece disposições relativas à política de regionalização das atividades administrativas do Estado no nível metropolitano, à Região Metropolitana de Belo Horizonte e seu modelo de gestão.

A ação dos órgãos de gestão da Região Metropolitana de Belo Horizonte abrange serviços e instrumentos que repercutem além do âmbito municipal e provoquem impacto no ambiente metropolitano, notadamente: no transporte intermunicipal, conexões intermodais, terminais e estacionamentos; no sistema viário de âmbito metropolitano, o controle de trânsito, tráfego e infraestrutura da rede de vias arteriais e coletoras; nas funções relativas à segurança pública; no saneamento básico; no uso do solo metropolitano; no aproveitamento dos recursos hídricos; na distribuição de gás canalizado; na cartografia e informações básicas; na preservação e proteção do meio ambiente e no combate à poluição; na habitação, as diretrizes para a localização habitacional e programas de habitação; no planejamento integrado do desenvolvimento sócio-econômico, a definição dos objetivos, estratégias e programas contidos no Plano Diretor Metropolitano.

Fundamentalmente, a gestão da Região Metropolitana de Belo Horizonte pelo Governo do Estado realiza-se mediante, principalmente, os seguintes instrumentos:

- autarquia estadual de planejamento da Região Metropolitana de Belo Horizonte, denominada Plambel e reorganizada através da Lei Estadual n. 11.474, de 26 de maio de 1994;

- Assembléia Metropolitana da Região Metropolitana de Belo Horizonte, órgão colegiado com poderes normativo e de gestão financeira dos recursos do Fundo de Desenvolvimento Metropolitano de Belo Horizonte, criado, nos termos da Constituição do Estado de Minas Gerais, por força da Lei Complementar Estadual n. 26, de 14 de janeiro de 1993.

À Assembléia Metropolitana de Belo Horizonte compete:

exercer o poder normativo regulamentar de integração do planejamento, da organização e da execução das funções públicas de interesse comum;

zelar pela observância das normas, mediante mecanismos específicos de fiscalização e controle dos órgãos e entidades metropolitanas;

elaborar e aprovar o Plano Diretor Metropolitano; 
- aprovar as políticas de aplicação dos investimentos públicos na Região Metropolitana de Belo Horizonte;

- promover as políticas de compatibilização de recursos de distintas fontes de financiamento destinados à implementação de projetos indicados no Plano Diretor Metropolitano;

- administrar o Fundo de Desenvolvimento Metropolitano da Região Metropolitana de Belo Horizonte;

- aprovar seu próprio orçamento anual no que se refere ao Fundo de Desenvolvimento Metropolitano;

- acompanhar e avaliar a execução do Plano Diretor Metropolitano, bem como aprovar as modificações que se fizerem necessárias à sua correta implementação;

aprovar os planos plurianuais de investimento e as diretrizes orçamentárias da Região Metropolitana de Belo Horizonte;

estabelecer as diretrizes da política tarifária dos serviços comuns de interesse metropolitano;

colaborar para o desenvolvimento institucional dos municípios que não disponham de capacidade de planejamento próprio;

- aprovar os balancetes mensais de desembolso e relatórios semestrais de desempenho do Fundo de Desenvolvimento Metropolitano;

aprovar os relatórios semestrais de avaliação de execução do Plano Diretor Metropolitano e de seus respectivos programas e projetos.

A Assembléia Metropolitana da Região Metropolitana de Belo Horizonte é composta dos prefeitos de cada um dos Municípios da Região Metropolitana, de vereadores de cada um destes Municípios em quantidade fixada proporcionalmente à respectiva população, de um representante da Assembléia Legislativa Estadual, designado pela Comissão de Assuntos Municipais e Regionalização do representante do Poder Executivo Estadual designado pelo Governador do Estado.

Além disso, a Assembléia Metropolitana, ao lado de sua Mesa Diretora, contém um Comitê Executivo composto pelos Prefeitos da Região Metropolitana de Belo Horizonte, e pelo representante do Poder Executivo Estadual e Câmaras Técnicas Setoriais Permanentes e Temporárias.

O Plambel, autarquia estadual de planejamento metropolitano, tem por finalidade o assessoramento para o planejamento, a organização, a coordenação e o 
controle das atividades setoriais a cargo do Estado relativas às funções públicas de interesse comum. Especificamente, dentre outras, tem a atribuição legal de coordenar a política estadual nos assuntos de interesse comum, de promover a implementação de planos, programas e projetos de investimento na Região Metropolitana de Belo Horizonte e de assessoramento à Assembléia Metropolitana na elaboração do Plano Urbanístico Metropolitano.

A Região Metropolitana de Recife RMR - teve seu modelo-gestão atualizado mediante a Lei Complementar Estadual n. 10, de 06 de janeiro de 1994. Esta lei complementar instituiu o modelo de gestão metropolitana integrado pelo:

- Conselho de Desenvolvimento da Região Metropolitana do Recife Conderm, órgão colegiado deliberativo vinculado à Secretaria de Planejamento do Estado;

- Fundação de Desenvolvimento da Região Metropolitana do Recife, criada pela Lei n. 6.890, de 03 de junho de 1975;

- Fundo de Desenvolvimento da Região Metropolitana do Recife, instituído pela Lei n. 7.003, de 02 de dezembro de 1975.

No Conderm participam os Prefeitos da Região Metropolitana do Recife e igual número de representantes do Poder Executivo Estadual. Como membros consultivos do Conderm participam também três deputados estaduais e um vereador representante de cada Câmara Municipal dos Municípios da Região Metropolitana do Recife. Câmaras Técnicas Setoriais apoiam o Conderm e suas deliberações e são compostas por 12 membros, sendo metade constituída por representantes do setor público, 2 do segmento empresarial e 2 do segmento acadêmico-profissional e 2 da comunidade.

Ao Presidente da Fundação de Desenvolvimento da Região Metropolitana do Recife, dentre outras atribuições, a Lei Complementar n. 10, de 06 de janeiro de 1994, determinou a gestão do Fundo de Desenvolvimento da Região Metropolitana do Recife, submetendo seus instrumentos e controle financeiro à deliberação do Conderm. Este Fundo, o Funderm, é constituído por receitas orçamentárias e outras oriundas de empréstimos e cobrança de taxas e contribuição de melhoria, as quais se destinam às atividades de planejamento do desenvolvimento da Região Metropolitana do Recife, à execução de funções públicas de interesse comum e à execução e operação de serviços urbanos de interesse metropolitano. 
No Estado de São Paulo, foi aprovado, com alterações, o projeto de lei complementar n. 19/91, que se transformou na Lei Complementar Estadual n. 760, de 04 de agosto de 1994, que fixa diretrizes para a organização regional.

Todavia, como a Constituição do Estado de São Paulo de 1989 exige a aprovação de leis complementares tanto para a criação de regiões metropolitanas quanto para a instituição dos respectivos modelos de gestão (criação da entidade pública territorial e o respectivo conselho normativo e deliberativo), bem como para a regulação da participação dos municípios e da sociedade civil no processo de gestão (art. 154), permanece sempre aberta a possibilidade de modificação das diretrizes estabelecidas na Lei Complementar Estadual n. 760, de 1994.

A propósito, novos projetos de lei complementar foram recentemente apresentados por deputados estaduais, desconsiderando as referidas "diretrizes" as quais, por sinal, estão fixadas na própria Constituição Estadual de 1989. Alguns destes projetos propõem a criação das regiões metropolitanas de Campinas e da Baixada Santista ao lado da atualização do superado modelo de gestão metropolitana da Grande São Paulo, enquanto outros pretendem a criação de diversas outras "regiões metropolitanas", como, por exemplo, as de Taboão da Serra e Itapeva, dentre outras, cuja realidade não se enquadra no conceito constitucional de região metropolitana formulado no $\S 1^{\circ}$ do art. 153, da Constituição Estadual.

Como conseqüência da instituição de autarquias metropolitanas poderá resultar uma descentralização do poder decisório, atualmente concentrado nas mãos do Governador do Estado, na medida em que os representantes dos municípios e da sociedade civil em cada região passam a ter peso efetivo nas decisões de interesse comum, deixando-se ao Chefe do Executivo Estadual as decisões estratégicas de maior relevância.

A titularidade do poder concedente em relação a funções públicas estaduais de interesse comum poderá ser delegada, mediante lei, para as entidades autárquicas metropolitanas, na qual os municípios e a sociedade civil disporão de melhores condições para interferir em sua gestão com vistas ao interesse coletivo. Esta delegação poderá efetuar-se sem prejuízo de que a execução dessas funções venha a ser desempenhada pela iniciativa privada, mediante concessão ou permissão.

Também o poder de polícia para aplicação de leis estaduais de ordenação e controle do uso do solo metropolitano poderá ser delegado às autarquias metropolitanas, mediante lei, avançando-se no processo de descentralização. 
Além disto, percebe-se uma tendência no sentido da explicitação exemplificativa, em lei, das funções de interesse comum em cada região ao lado de suas principais características norteadoras: "...consideram-se de interesse comum as funções e os serviços públicos que, ou atendam a mais de um município, ou, mesmo restritos ao território de um deles, provoquem impacto ou repercutam além do âmbito municipal..."

No atual federalismo brasileiro, a gestão metropolitana situa-se no âmbito das atribuições constitucionais do Estado Federado, não sendo compatível com ele a criação de uma "federação de municípios" ou de uma entidade metropolitana inteiramente desvinculada do Estado Federado, como propugnam alguns urbanistas, ressalvada a hipótese de emenda à Constituição Federal. A formação de consórcios entre municípios é juridicamente possível, podendo conviver com a criação pelo Estado Federado de entidade pública metropolitana. Neste caso, esta última disporá de poderes e prerrogativas de direito público que se sobrepõem à atuação dos consórcios. Ademais, estes constituem meras associações de municípios para execução de serviços e atividades comuns, podendo cada município consorciado dele se retirar a qualquer tempo. Em conseqüência, esta forma de associação municipal (consórcio) padece de uma debilidade congênita que não a torna apta para satisfazer, com estabilidade institucional, interesses públicos supramunicipais, ainda mais, num contexto em que se sujeita, por força da Constituição brasileira, ao controle e à disciplina do respectivo Estado Federado.

Existem ainda aqueles que defendem a possibilidade de qualquer município metropolitano ingressar ou sair de sua região metropolitana mediante plebiscito. Esta tese não se coaduna com o federalismo brasileiro, que atribui ao Estado Federado a responsabilidade pela solução dos problemas coletivos supramunicipais, dentre os quais se incluem os metropolitanos, quer crie ou-não regiōes metropolitanas. Estas unidades territoriais estaduais constituem primeiramente fenômenos geográficos, econômicos, urbanísticos e sociais. Somente num segundo momento surge a questão do seu reconhecimento jurídico-institucional para o fim de descentralização administrativa e gestão estadual regionalizada. 
II A organização regional na Constituição do Estado de São Paulo

A organização regional é imprescindível para tais objetivos e ao Estado-membro foi atribuída a competência para instituir regiões metropolitanas, aglomerações urbanas e microrregiões, "constituídas por agrupamentos de municípios limitrofes, para integrar a organização, o planejamento e a execução de funções públicas de interesse comum" (art. $25, \S 3^{\circ}$ ).

O Estado de São Paulo no exercício de sua autonomia constitucional dispôs sobre a ordenação de seu território (art. 153, da Constituição Estadual):

"Parágrafo $1^{o}$ Considera-se região metropolitana o agrupamento de Municípios limítrofes que assuma destacada expressão nacional, em razão de elevada densidade demográfica, significativa conurbação $e$ de funções urbanas $e$ regionais com alto grau de diversidade, especialização e integração sócioeconômica, exigindo planejamento integrado e ação conjunta permanente dos entes públicos nela atuantes.

Parágrafo $2^{\circ}$ Considera-se aglomeração urbana $o$ agrupamento de Municípios limítrofes que apresente relação de integração funcional de natureza econômicosocial e urbanização contínua entre dois ou mais Municípios ou manifesta tendência nesse sentido, que exija planejamento integrado e recomende ação coordenada dos entes públicos nela atuantes.

Parágrafo $3^{\circ} \quad$ Considera-se microrregião $o$ agrupamento de Municípios limítrofes que apresente, entre si, relações de interação funcional de natureza físico-territorial, econômico-social e administrativa, exigindo planejamento integrado com vistas a criar condições adequadas para o desenvolvimento $e$ integração regional."

Para o estabelecimento de entidades regionais e respectivas gestão dispõe o art. 154 da Constituição do Estado de São Paulo, que será criado em cada 
"unidade regional, um conselho de caráter normativo deliberativo, bem como disporá sobre a organização, a articulação, a coordenação e, conforme o caso, a fusão de entidades ou órgãos públicos atuantes na região, assegurada nestes $e$ naquele, a participação paritária do conjunto dos Municípios, com relação ao Estado" (grifos nossos)

No caso das regiões metropolitanas, o Conselho normativo e deliberativo (art. 154) "integrará entidade pública de caráter territorial, vinculando-se a ele os respectivos órgãos de direção e execução, bem como as entidades regionais e setoriais executoras das funções públicas de interesse comum, no que respeita ao planejamento e às medidas para sua implementação" (art. 154, § $\left.1^{\circ}\right)$.

A participação popular também é garantida desde o processo de planejamento até a tomada de decisões, incluindo a "fiscalização da realização de serviços ou funções públicas em nível regional" (art. 154, § $2^{\circ}$ ).

A eficácia das disposições constitucionais dependerá de leis complementares estaduais para a descentralização e a devida integração do planejamento e das funções públicas de interesse comum, regras que informarão a institucionalização e gestão das unidades regionais.

Todavia, a regionalização deve aquiescer aos princípios constitucionais e aos fins ali colimados, conforme se comentou. O federalismo cooperativo requer atuação conjunta e sobretudo respeitosa entre o Estado e os Municípios. Inexiste hierarquia entre as entidades federadas.

\section{A Constituição Estadual e a Lei Complementar n. 760/94}

Diante de tais disposições, algumas normas da Lei Complementar Estadual n. 760/94 permanecem conflitantes com os princípios e objetivos constitucionais, na medida em que extrapolam diretrizes e regram especificidades, comprometendo a autonomia dos Municípios com prejuízo à regionalização necessária.

$\mathrm{O}$ art. $6^{\circ}$ desta lei complementar prevê a exigência de parecer prévio da Secretaria Estadual de Planejamento para tornar possível a apresentação de projeto de lei complementar com o objetivo de criação de região metropolitana, aglomeração urbana ou microrregião. Este preceito restringe, portanto, o poder de 
iniciativa legislativa dos deputados estaduais e dos cidadãos garantido pelo art. 24 da Constituição Estadual.

Seu art. $9^{\circ}$ trata da composição dos conselhos de desenvolvimento, gestores das unidades regionais, determinando que sejam formados por um representante de cada Município e que as integre por "representantes dos Estados nos campos funcionais de interesse comum" "assegurada a participação paritária do conjunto dos Municípios em relação ao Estado no Conselho de Desenvolvimento de cada região"

Esses ditames regulamentam de forma restritiva a participação paritária na gestão dos entes regionais, pois se o princípio é a democratização participativa dos Municípios e do povo, nada obsta, mas claramente se entende que o constituinte estabeleceu a um "minimum" passível de ser aperfeiçoado, ampliado e diversificado quando da regionalização. Urge buscar democraticamente os objetivos constitucionais, tanto que, se conveniente for, podem ser aumentados os representantes dos Municípios e de segmentos organizados da sociedade civil. Ademais, o art. 294 da Constituição Estadual assegura a participação da sociedade civil nos conselhos nela previstos. Desse modo, poderão ocorrer avanços no sentido da concretização dos princípios constitucionais da democracia participativa semidireta.

A análise dessas normas à luz dos objetivos e princípios constitucionais revela uma descentralização com transferência do poder decisório, com fundamental participação dos municípios no processo de tomada de decisões, sem prejuizo da coordenação constitucional prevista.

A paridade assegurada ao conjunto dos Municípios em relação ao Estado (art. 154, caput), não exclui a participação popular (art. $154, \S 2^{\circ}$ ), pois a interpretação deve embasar-se nos princípios democráticos acolhidos pela Constituição. As Leis Complementares que instituírem as respectivas regiões deverão disciplinar a composição do Conselho de Desenvolvimento.

Saliente-se ainda o tratamento dado à participação popular nos Conselhos de Desenvolvimento pelo art. 14 da citada Lei Complementar Estadual n. 760/94. Estabeleceu quatro determinações, chamadas em lei por "princípios": divulgação dos planos, programas, projetos e propostas com antecedência mínima de trinta dias; acesso aos estudos de viabilidade técnica, econômica, financeira e ambiental; possibilidade de representação por discordância e de comparecimento à reunião do Conselho para sustentação e possibilidade de solicitação de audiência 
pública para esclarecimentos. Como se deduz trata-se de verdadeiros procedimentos fiscalizatórios, e não princípios, ou seja, aquele que informa ou no qual se baseiam as ações.

Conforme o jus-administrativista Celso Antonio Bandeira de Mello, princípio jurídico é "mandamento nuclear de um sistema, verdadeiro alicerce dele, disposição fundamental que se irradia sobre diferentes normas compondo-lhes o espírito e servindo de critério para sua exata compreensão $e$ inteligência, exatamente por definir a lógica e a racionalidade do sistema normativo, no que lhe confere a tônica e lhe dá sentido harmônico" ${ }^{1}$ Nesse sentido entendem-se os princípios fundamentais da Constituição de 1988, conforme analisa o jusconstitucionalista José Afonso da Silva quanto aos princípios relativos ao regime político: ${ }^{2}$ princípio da cidadania, princípio da dignidade da pessoa, princípio do pluralismo, princípio da soberania popular, princípio da representação política e princípio da participação popular direta (art. $1^{\circ}$, parágrafo único). Como princípios, dão coerência e integram as normas constitucionais. $\mathrm{O}$ regime político é democrático e como princípio constitucional fundamental informa todo o ordenamento jurídico.

$\mathrm{O}$ regime democrático vigente introduziu mecanismos de democracia semidireta, além da escolha de representantes políticos. O povo (conjunto dos cidadãos e titular da soberania do Estado) opinará sobre questões políticas mediante consulta plebiscitária; ou referendará propostas políticas; sendo-lhe facultada a iniciativa popular para apresentação de projeto de lei (art. $1^{\circ}$, parágrafo único, arts. 14 e $61, \S 2^{\circ}$ : todos da Constituição Federal). Tais normas vêm viabilizar o exercício do direito fundamental à participação política, ou seja, o direito de o cidadão organizar a vida em sociedade e gerir a coisa pública. Trata-se de direito implícito, decorrente dos princípios democráticos adotados na Constituição, como dispõe o art. $5^{\circ}, \S 2^{\circ}$ :

\section{"Os direitos e garantias expressos nesta Constituição} não excluem outros decorrentes do regime e princípios por ela adotados, ou dos tratados internacionais em que a República Federativa do Brasil seja parte."

1. Mello, Celso Antonio Bandeira, Elementos de Direito Administrativo, São Paulo, RT, 1980, p. 230. Apud José Afonso da Silva, Curso de Direito Constitucional Positivo, São Paulo, RT, 1990, pp. $81-2$.

2. Silva, José Afonso da, Curso de Direito Constitucional Positivo, São Paulo, RT, 1990, p. 84. 
Também neste caso o constituinte foi melhor que o legislador, pois a Constituição Estadual garante a participação popular desde o processo de planejamento regional até a tomada de decisões, incluindo a fiscalização (art. 154, § $2^{\circ}$ ), enquanto o legislador restringe a fiscalização consentida (art. 14, Lei Complementar n. 760/94).

A participação popular na regionalização e na gestão das entidades regionais deve ocorrer a partir dos princípios constitucionais, ensejando interpretação a mais democrática das normas constitucionais. Nada impede, portanto, claramente insinua, venha integrar os Conselhos de Desenvolvimento a sociedade organizada, com suas diversificadas associações, ou, até mesmo, cidadãos eleitos diretamente pela população por sub-regiões de cada região metropolitana, dando assim eficácia a participação democrática garantida pela Constituição.

Outra questão relevante na composição dos Conselhos de Desenvolvimento diz respeito à participação dos membros do Legislativo como representantes do Estado (deputados) ou dos Municípios (vereadores).

A doutrina de separação dos poderes do Estado, criação magistral de pensadores políticos (Aristóteles, John Locke, Montesquieu) erigiu-se em doutrina a inspirar revolucionários liberais e constituintes. $\mathrm{O}$ enfrentamento ao poder abusivo, ilimitado, elevou a doutrina a princípio democrático. Pressupõe a tripartição das funções do Estado que teve função política vital para a afirmação do regime político democrático em oposição ao poder absoluto dos governantes. Desse modo, a separação, como distinção de funções exercidas por órgãos distintos, pressupõe a interferência de um poder sobre o outro de modo que cada um limite o poder dos demais num sistema de freios e contrapesos.

Todavia, é também da doutrina clássica (Jean Bodin) que extraímos o conceito e características do poder do Estado, a soberania; "poder absoluto $e$ perpétuo de uma República". Trata-se do "poder de organizar-se juridicamente e de fazer valer dentro de seu território a universalidade de suas decisões nos limites dos fins éticos de convivência". ${ }^{3}$ Uno, indivisível, inalienável e imprescindível é o poder do Estado. O que se reconhece são funções públicas a serem desenvolvidas pelo Estado no exercício de sua soberania.

3. Bodin, Jean, As Leis Livres da República (1583) e Reale, Miguel, Teoria do Direito e do Estado, São Paulo, Martins, 1960, p. 127. Apud Dalmo de Abreu Dallari, Elementos de Teoria Geral do Estado, São Paulo, Saraiva, 1989. 
São oportunas as observações do jus-constitucionalista, Manoel Gonçalves Filho:

"Em realidade, essa tripartição não tem o rigor necessário para ser acatada como científica. De fato, é fácil mostrar que as funções administrativa $e$ jurisdicional têm no fundo a mesma essência, que é a aplicação da lei a casos particulares. A distinção entre ambas pode estar no modo, no acidental, portanto, já que substancialmente não existe. Por outro lado, a função legislativa não esgota a edição de regras gerais $e$ impessoais. Tradicionalmente inclui-se na função administrativa o estabelecimento de regulamentos, cujo conteúdo são também regras gerais e impessoais". ${ }^{4}$

$\mathrm{Na}$ atualidade, observa-se verdadeira interpenetração no exercício dessas funções (cujo disciplinamento constitucional, revela exercício de função pública e não exercício de "poder"), devido às diversificadas tarefas assumidas pelo Estado. Na gênese do Estado democrático a contribuição de Montesquieu já previa e consta das Constituições, a participação conjunta do Legislativo e Executivo no processo legislativo, mediante o exercício do veto. Ou mesmo quando sanciona é o Executivo que transforma o projeto de lei, já aprovado pelo Legislativo, em lei e assim a promulga. Podendo essa interpenetração ocorrer entre órgãos públicos do mesmo nível de governo (Executivo e Legislativo Federal) ou entre outros níveis de governo (Executivo Estadual e Legislativo Municipal ou vice-versa).

A Constituição Federal de 1988, ainda se utiliza das nomenclaturas Poder Legislativo, Poder Executivo e Poder Judiciário por ação de forças conservadoras atuantes no período constituinte. Constituições contemporâneas, também precedidas de movimentos populares, pró-constituinte, como a de Portugal (1976, 1982) e Espanha (1974) não fazem uso dessas denominações. Assim, a Constituição brasileira prevê a interpenetração das funções ao permitir que deputados e senadores possam exercer os Ministérios (art. 54) ou Secretarias de Estado ou vereadores integrarem o Secretariado nos Municípios. Atribui ao

4. Ferreira Filho, Manoel Gonçalves, Curso de Direito Constitucional, São Paulo, Saraiva, 1989, p. 118. 
Legislativo (Câmara dos Deputados e Senado Federal, art. 50) a convocação de Ministros de Estado para prestação de informações sobre assuntos relevantes. E por fim temos o Presidente da República exercendo atos com força de lei, as medidas provisórias (art. 62) e o Judiciário, administrando suas secretarias e propondo projetos de lei (arts. 61, 93).

O próprio Executivo federal terá em seus órgãos superiores de consulta membros do Legislativo. Assim o Conselho da República (art. 89) terá entre seus membros deputados, senadores e cidadãos (Presidente do Senado Federal, Presidente da Câmara dos Deputados, os líderes da maioria e da minoria, de ambas as Casas do Legislativo e seis cidadãos brasileiros natos). O Conselho de Defesa Nacional (art. 91) também terá como membros obrigatórios os Presidentes do Senado Federal e da Câmara dos Deputados. Muitos são os exemplos da atuação entre membros das funções públicas fundamentais.

O jurista português J.J. Gomes Canotilho ao comentar a Constituição portuguesa contemporânea à brasileira lembra que Constituição não é mero estatuto organizatório e sim instrumento de governo ${ }^{5}$ e portanto a todos vincula: não há poderes mas sim funções governamentais relevantes; trata-se de deveres, tarefas específicas com finalidades próprias.

$\mathrm{Na}$ vinculação constitucional as funções governamentais devem funcionar em cooperação, tendo em vista as prestações positivas atribuídas ao Estado.

Portanto, conforme princípios e objetivos constitucionais, já comentados, e às novas exegeses da interpenetração das funções públicas do Estado, membros do Legislativo podem integrar os Conselhos de Desenvolvimento na gestão das funções públicas regionais.

A Lei Complementar Estadual n. 760/94 estabeleceu as diretrizes para a organização regional, praticamente, repetindo a Constituição Estadual, porém, em muitas normas extrapolou suas funções restringindo princípios constitucionais democráticos, bem como a autonomia municipal.

Tal situação poderá ser enfrentada e corrigida por leis estaduais do mesmo nível, ou seja, pelas leis complementares estaduais que instituírem regiões metropolitanas, aglomerações urbanas e microrregiões (art. $25, \S 3^{\circ}$, Constituição

5. Canotilho, José Joaquim Gomes, Constituição Dirigente e Vinculação do Legislador, Coimbra, Coimbra, 1983. 
Federal) ou adaptarem à nova ordem constitucional, regiões metropolitanas, já existentes. É o caso das futuras Regiões Metropolitanas de Santos e de Campinas e a adaptação da Região Metropolitana da Grande São Paulo, criada sob a égide da Constituição anterior.

Nada obsta a elaboração de novas disposições quanto à composição dos membros do Conselho de Desenvolvimento, proporcionando maior número de representantes aos Municípios participantes, ou quanto à participação popular, permitindo aos cidadãos ou associações integrarem o Conselho, atendendo aos princípios do federalismo cooperativo e do regime democrático. A atuação conjunta de membros do Executivo e do Legislativo nos Conselhos de Desenvolvimento, também revela entendimento atualizado e progressista das principais funções públicas do Estado. Portanto, os princípios da legalidade e da participação popular devem informar o legislador estadual ao criar ou adaptar os entes regionais.

\section{A questão da compatibilização e articulação com outros Conselhos Estaduais}

No Estado de São Paulo constata-se uma situação de fato em relação às bases territoriais dos sistemas estaduais de gestão de recursos hídricos, de saneamento, ambiental e de desenvolvimento urbano e sócio-econômico.

No caso dos primeiros (recursos hídricos, saneamento e meio ambiente) considera-se como unidade territorial a bacia hidrográfica, cujos limites, em regra, não-coincidem com os limites territoriais político-administrativos que distinguem os municípios uns dos outros. No caso do desenvolvimento regional e urbano as unidades territoriais são determinadas com base nos critérios estabelecidos no art. 153 da Constituição Estadual.

Os conselhos de articulação intergovernamental nas regiões metropolitanas, aglomerações urbanas e microrregiões estão previstos no art. 154 da Constituição Estadual.

O Conselho Estadual do Meio Ambiente Consema, órgão normativo e recursal está previsto no parágrafo único do art. 193 da Constituição Estadual. Por outro lado, os Comitês de Bacia Hidrográfica, integrantes do sistema estadual de gestão dos recursos hídricos estão previstos na Lei Estadual n. 7.663, de 30 de dezembro de 1991. 
Neste contexto, torna-se extremamente difícil a perfeita coincidência destas bases territoriais para fins de planejamento e descentralização da ação do Governo estadual.

Em última instância, cabe ao Chefe do Poder Executivo Estadual o Governador - a compatibilização das deliberações desses órgãos colegiados regionais na medida em que, nos termos do inciso II do art. 47 da Constituição Estadual, lhe compete exercer, com o auxílio dos Secretários de Estado, a direção superior da Administração estadual.

Além disto, no âmbito metropolitano propriamente dito, o modelo de gestão deve ser suficientemente flexível para incorporar o tratamento diferenciado de temas que afetem apenas um grupo reduzido de municípios das regiões metropolitanas. Neste sentido, deve admitir a possibilidade de criação de órgãos colegiados temáticos ou setoriais e sub-regionais para o equacionamento de questões específicas de interesse comum em articulação com o conselho normativo e deliberativo metropolitano.

São Paulo, janeiro de 1996.

\section{BIBLIOGRAFIA}

ALMEIDA, Fernanda Dias Menezes de. Competências na Constituição de 1988. São Paulo : Atlas, 1991.

BASTOS, Celso. Curso de Direito Constitucional. São Paulo : Saraiva, 1990.

BOBBIO, Norberto. A teoria do ordenamento jurídico. Trad. Cláudio de Cicco e Maria Celeste C.J. Santos. São Paulo : Pólis e UnB, 1989.

CANOTILHO, José Joaquim Gomes. Constituição Dirigente e Vinculação do Legislador Contributo para a compreensão das normas constitucionais programáticas. Coimbra : Coimbra, 1982.

DALLARI, Dalmo de Abreu. Elementos de Teoria Geral do Estado. São Paulo : Saraiva, 1990.

DALLARI, Dalmo de Abreu. O Estado Federal. São Paulo : Ática, 1986.

FERRAZ, Anna Cândida da Cunha. União, Estados e Municípios na Nova Constituição: enfoque jurídico-formal. In: A Nova Constituição Paulista. São Paulo : Fundação Faria Lima e Fundação de Desenvolvimento Administrativo, 1989. 
FERREIRA FILHO, Manoel Gonçalves. Curso de Direito Constitucional. São Paulo : Saraiva, 1989.

Saraiva, 1990.

GRAU, Eros Roberto. Planejamento econômico e regra jurídica. São Paulo : Revista dos Tribunais, 1978.

LOMAR, Paulo José Villela; DI GIORGIO, Beatriz Maria G.; MATSCHINSKE, Maria Liliane e PRUDENTE, Eunice Aparecida de Jesus. Legislação básica de interesse para o planejamento metropolitano do Estado de São Paulo. São Paulo : Empresa Metropolitana de Planejamento da Grande São Paulo S.A. Emplasa, 1994.

MEIRELLES, Hely Lopes. Direito Administrativo Brasileiro. São Paulo : Revista dos Tribunais, 1989.

MELLO, Celso Antonio Bandeira. Elementos de Direito Administrativo. São Paulo : Revista dos Tribunais, 1980.

PIOVESAN, Flávia C. Constituição e Transformação Social: eficácia das normas constitucionais programáticas e a concretização dos direitos e garantias fundamentais. In: Revista da Procuradoria do Estado de São Paulo, 1993. v. 37.

SILVA, José Afonso da. Curso de Direito Constitucional Positivo. São Paulo : Revista dos Tribunais, 1990.

Tribunais, 1981.

Direito Urbanístico Brasileiro. São Paulo : Revista dos 